\title{
Effect of pay for performance on the management and outcomes of hypertension in the United Kingdom: interrupted time series study
}

\section{Citation}

Serumaga, B., D. Ross-Degnan, A. J. Avery, R. A. Elliott, S. R. Majumdar, F. Zhang, and S. B. Soumerai. 2011. "Effect of Pay for Performance on the Management and Outcomes of Hypertension in the United Kingdom: Interrupted Time Series Study." BMJ 342 (jan25 3) (January 25): d108-d108. doi:10.1136/bmj.d108.

\section{Published Version}

doi:10.1136/bmj.d108

\section{Permanent link}

http://nrs.harvard.edu/urn-3:HUL.InstRepos:32692211

\section{Terms of Use}

This article was downloaded from Harvard University's DASH repository, and is made available under the terms and conditions applicable to Other Posted Material, as set forth at http:// nrs.harvard.edu/urn-3:HUL.InstRepos:dash.current.terms-of-use\#LAA

\section{Share Your Story}

The Harvard community has made this article openly available.

Please share how this access benefits you. Submit a story.

Accessibility 


\title{
BMJ
}

\section{Effect of pay for performance on the management and outcomes of hypertension in the United Kingdom: interrupted time series study}

\author{
Brian Serumaga, Harvard Medical School fellow in pharmaceutical policy research, ${ }^{1,2}$ Dennis Ross-Degnan, \\ associate professor and director of research, ${ }^{1}$ Anthony J Avery, professor, ${ }^{2}$ Rachel A Elliott, professor, ${ }^{3}$ Sumit \\ R Majumdar, professor, ${ }^{4}$ Fang Zhang, statistician and instructor, ${ }^{1}$ Stephen B Soumerai, professor ${ }^{1}$
}

${ }^{1}$ Department of Population Medicine, Harvard Medical School and Harvard Pilgrim Health Care Institute, 133 Brookline Avenue,

Boston, MA 02215, USA

${ }^{2}$ Division of Primary Care,

University of Nottingham Medical School, UK

${ }^{3}$ Division of Social Research in Medicines and Health, University of Nottingham School of Pharmacy, UK

${ }^{4}$ Department of Medicine, University of Alberta, Canada

Correspondence to: S B Soumerai stephen_soumerai@hms.harvard. edu

Cite this as: $B M J$ 2011;342:d108 doi:10.1136/bmj.d108

\section{ABSTRACT}

Objective To assess the impact of a pay for performance incentive on quality of care and outcomes among UK patients with hypertension in primary care.

Design Interrupted time series.

Setting The Health Improvement Network (THIN) database, United Kingdom.

Participants 470725 patients with hypertension diagnosed between January 2000 and August 2007. Intervention The UK pay for performance incentive (the Quality and Outcomes Framework), which was implemented in April 2004 and included specific targets for general practitioners to show high quality care for patients with hypertension (and other diseases).

Main outcome measures Centiles of systolic and diastolic blood pressures over time, rates of blood pressure monitoring, blood pressure control, and treatment intensity at monthly intervals for baseline (48 months) and 36 months after the implementation of pay for performance. Cumulative incidence of major hypertension related outcomes and all cause mortality for subgroups of newly treated (treatment started six months before pay for performance) and treatment experienced (started treatment in year before January 2001) patients to examine different stages of illness.

Results After accounting for secular trends, no changes in blood pressure monitoring (level change 0.85, 95\% confidence interval -3.04 to $4.74, \mathrm{P}=0.669$ and trend change $-0.01,-0.24$ to $0.21, P=0.615)$, control $(-1.19$, -2.06 to $1.09, P=0.109$ and $-0.01,-0.06$ to 0.03 , $\mathrm{P}=0.569)$, or treatment intensity $(0.67,-1.27$ to 2.81 , $\mathrm{P}=0.412$ and $0.02,-0.23$ to $0.19, \mathrm{P}=0.706$ ) were attributable to pay for performance. Pay for performance had no effect on the cumulative incidence of stroke, myocardial infarction, renal failure, heart failure, or all cause mortality in both treatment experienced and newly treated subgroups.

Conclusions Good quality of care for hypertension was stable or improving before pay for performance was introduced. Pay for performance had no discernible effects on processes of care or on hypertension related clinical outcomes. Generous financial incentives, as designed in the UK pay for performance policy, may not be sufficient to improve quality of care and outcomes for hypertension and other common chronic conditions.

\section{INTRODUCTION}

Since 2000 the use of pay for performance policies that link a portion of doctors' payment to measures of healthcare quality has increased rapidly. Both governments and private payers have promoted pay for performance in the belief that economic incentives can accelerate improvements in the quality and outcomes of care. Surprisingly, there is little rigorous evidence to support or refute use of these policies. ${ }^{1}$ Indeed, pay for performance schemes may result in unintended outcomes as a result of adverse selection, such as the exclusion of severely ill patients from care..$^{2-4}$

The impacts of pay for performance on the quality and outcomes of care for common chronic conditions such as hypertension are largely unknown. The prevalence of hypertension among those over age 50 is about $50 \%$; hypertension is among the most treatable, but undertreated, of cardiovascular risk factors. ${ }^{5}$ Studies indicate consistently that one third of people with a known diagnosis of hypertension are either untreated or uncontrolled. $^{67}$ Better control of hypertension on a population-wide basis could yield substantial reductions in morbidity and premature mortality, ${ }^{68}$ and this also makes it an attractive target for pay for performance.

We studied a large scale pay for performance policy in the four countries of the United Kingdom (England, Scotland, Wales, and Northern Ireland), which targeted several chronic diseases in primary care, and evaluated its impact on the management and outcomes of hypertension. Based on the proportion of patients achieving certain quality indicators, general practitioners could receive payments as high as 25\% of their total income. ${ }^{9}$ The programme started in April 2004 and included 136 quality indicators, including five for hypertension (see web extra), one of which was the proportion of patients with blood pressures controlled to $150 / 90 \mathrm{~mm} \mathrm{Hg}$ or less. ${ }^{10}$ 
Characteristics of overall study population and subgroups of newly treated and treatment experienced patients. Values are numbers (percentages) unless stated otherwise

\begin{tabular}{|c|c|c|c|}
\hline Characteristics & $\begin{array}{l}\text { Overall study } \\
\text { population } \\
(n=470725)\end{array}$ & $\begin{array}{l}\text { Newly treated } \\
\text { subgroup* } \\
(n=103009)\end{array}$ & $\begin{array}{c}\text { Treatment experienced } \\
\text { subgroup } \dagger \\
(n=104754)\end{array}$ \\
\hline Overall mean (SD) age & $58.3(15.4)$ & $58.1(15.6)$ & $56.7(15.3)$ \\
\hline \multicolumn{4}{|c|}{ Mean (SD) age (years) by age group: } \\
\hline$<55$ & $184524(39.2)$ & $41018(39.8)$ & $45546(43.5)$ \\
\hline $55-64$ & $116739(24.8)$ & $25033(24.3)$ & $24445(23.3)$ \\
\hline $65-74$ & $102618(21.9)$ & $21628(21.0)$ & $21856(20.9)$ \\
\hline$\geq 75$ & $66372(14.1)$ & $15330(14.9)$ & 12907 (12.32) \\
\hline Female & $259714(55.2)$ & $57527(55.9)$ & $59977(57.3)$ \\
\hline Mean (SD) body mass index & $28.9(5.2)$ & $28.6(5.7)$ & $29.1(5.6)$ \\
\hline Diabetes & $68867(16.6)$ & $15813(15.4)$ & $17614(16.8)$ \\
\hline Myocardial infarction $\ddagger$ & $24797(5.27)$ & $898(0.87)$ & $1896(1.81)$ \\
\hline Depression & $112752(23.9)$ & $23532(22.8)$ & $25335(24.2)$ \\
\hline Stroke & $37789(8.0)$ & $2313(2.25)$ & $4362(4.16)$ \\
\hline Smokers & $146561(31.1)$ & $34227(33.2)$ & $34339(32.8)$ \\
\hline Alcohol misuse & $78389(16.7)$ & $19127(18.6)$ & 20664 (19.7) \\
\hline Heart failure & $24007(5.1)$ & $1154(1.12)$ & $2726(2.6)$ \\
\hline Renal failure & $10827(2.3)$ & $980(0.95)$ & $1690(1.61)$ \\
\hline Lowest socioeconomic status§ & $53157(11.3)$ & $11297(8.0)$ & $11336(10.8)$ \\
\hline
\end{tabular}

*Cohort followed up for 45 months from October 2003 to July 2007.

†Cohort followed up for 80 months from January 2001 to July 2007.

¥Both cohorts do not add up to $100 \%$ because only newly treated patients in pre-intervention period are

included. Higher proportion of outcomes in treatment experienced cohort is due to longer follow-up.

$\S$ Socioeconomic status according to fifths of Townsend's deprivation index.

This natural experiment was ideal for detecting the effects of pay for performance on the care and outcomes of hypertension. Although the programme was voluntary, $99.6 \%$ of general practitioners participated. ${ }^{11}$ The financial incentives for doctors to achieve the quality standards were substantial; the UK National Health Service committed $£ 1.8 \mathrm{bn}(€ 2.1 \mathrm{bn} ; \$ 2.8 \mathrm{bn})$ in funding. ${ }^{12}$ Almost simultaneously (June 2004) the National Institute for Health and Clinical excellence (NICE) released guidelines for the detection and management of hypertension, which were consistent with the pay for performance intervention guidance and may have also reinforced the intervention. ${ }^{13}$ Using data obtained from representative primary care practices in the United Kingdom, we evaluated whether the introduction of pay for performance had an impact on quality of care for hypertension and the risk of major adverse clinical outcomes.

\section{METHODS}

We used data from The Health Improvement Network (THIN), a large database of primary care medical records, with about 6.2 million patient years from 358 general practices in the United Kingdom. ${ }^{14}$ The database contains validated sociodemographic records of patients as well as the results of medical tests, diagnoses, free text comments, and prescriptions written during medical practice at the level of individual patient visits. These data also include reports on episodes of secondary care (for example, hospital admissions, emergency care) as well as information on referral to specialists and some lifestyle characteristics and measurements, such as smoking status and body mass index. The data provide a longitudinal record of care for each patient. The database is nationally representative and has been used in several published studies of chronic conditions. ${ }^{14-17}$

Our study sample consisted of 470725 patients with a diagnosis of hypertension during the observation period (January 2000 to July 2007). Similar to our previous studies on drug use and clinical outcomes, we chose a common condition and a large sample to maximise precision and achieve stable estimates of study outcomes. ${ }^{18-20}$ We used a previously validated algorithm to define hypertension, using diagnostic Read codes (clinical terms version 3, categories G20 and 662..) in the patient records. ${ }^{1721} \mathrm{We}$ defined diagnosis as the presence of at least two diagnostic Read codes for hypertension; treatment initiation was defined as the date of the first prescription. We excluded 762 patients of non-permanent registration status (such as temporary residents or visitors) or who had changed practice before 1 January 2000.

\section{Study design}

From THIN we extracted data on visits to primary care for seven years. We measured changes in processes of care (frequency of treatment initiation and monitoring, intensity of prescribing), intermediate outcomes (centiles of blood pressure, rate of hypertension control), and clinical outcomes (all cause mortality, incidence of hypertension related adverse outcomes: myocardial infarction, heart failure, stroke, and renal failure), three years before, and up to four years after, the implementation of pay for performance.

\section{Statistical analyses}

We used interrupted time series analysis, a strong longitudinal quasi-experimental design, to evaluate the impact of the pay for performance initiative on the management and outcomes of hypertension. ${ }^{22}$ Using segmented linear regression models we examined the frequency of blood pressure measurement and the proportion of patients with controlled blood pressure each month, which were incentivised directly in the pay for performance initiative for hypertension. In addition, we examined changes in the rates of new treatment for hypertension and intensity of prescribing (that is, use of combination therapy), which were not incentivised in pay for performance. We hypothesised that these may have been affected indirectly as general practitioners strove to meet the incentivised targets for hypertension. Controlling for baseline level and trend we used these models to estimate the changes in levels and trends of rates after the implementation of pay for performance. ${ }^{23}$ For each time series model we included an extensive preintervention period to control for biases in level and trend at baseline.

We used segmented survival analysis to assess the impact of the intervention on the cumulative incidence and monthly proportions of hypertension related outcomes. ${ }^{19}$ The hypertension prescribing guidelines published by NICE in June 2004 were issued in the same quarter as the roll-out of the pay for performance 
initiative, and the various indicators we examined were consistent with these guidelines. To limit cointervention confounding of the time series we therefore defined April to June 2004 as the intervention phase-in period. ${ }^{24}$ We evaluated each aggregated time series model for confounding by seasonality. ${ }^{24}$

We used SAS software, version 9.1, for all analyses. Our data consisted of continuous measurements of variables at the population level, summarised at regular, evenly spaced time intervals, making them suitable for interrupted time series analysis. Because we used aggregated time series data at population level, our analyses were not affected by clustering bias. ${ }^{24} \mathrm{We}$ converted all time series of blood pressure control, frequency of blood pressure measurements, number of drug categories prescribed, and number of newly treated patients (treatment started six months before the introduction of pay for performance) to rates by dividing the total for each month by the number of patients enrolled in the cohort for that month. To estimate changes in these rates for all groups after the intervention, we used segmented linear regression models controlling for level and trend before the implementation of pay for performance. ${ }^{1922}$ The basic model included terms to estimate the pre-existing level for each rate in the first month of the observation period (intercept), trend in the rate before implementation of pay for performance, change in level of the rate immediately after implementation, and change in trend after implementation. We corrected the models for the serially autocorrelated nature of the observations. ${ }^{24}$ To identify the most parsimonious models we used backward elimination.

We used Cox proportional hazards regression models to obtain cumulative incidence rates of all cause mortality, myocardial infarction, stroke, heart failure, and renal failure for both newly treated and treatment experienced cohorts, adjusting for age, sex, smoking status, diabetes, depression, and body mass index at entry into the study cohort. ${ }^{2526}$ Specifically, we defined the newly treated cohort as patients who started treatment in the 12 months before October 2003 (six months before pay for performance) and followed them for up to 45 months until July 2007. The treatment experienced cohort included patients who started treatment in the 12 months before January 2001. We followed this cohort for up to 80 months until July 2007. We ran the analyses using data from patients with only complete information for all variables (78\% of the total sample). To determine whether the hazard ratios for each hypertension related outcome differed before and after the implementation of pay for performance we fitted extended piecewise Cox models ${ }^{25}$ in separate models for the two cohorts, which allow for fixed and time dependent covariates and for different hazard ratios in different time segments. We censored patients at the date of the occurrence of the first hypertension related outcome, date of death, date of loss to follow-up (for example, relocation), or end of study period.

\section{Blood pressure measures}

Blood pressure represents the principal dependent variable for this study, as general practitioners were incentivised directly to lower blood pressure to 150 / $90 \mathrm{~mm} \mathrm{Hg}$ or less (see web extra).

We extracted records of blood pressure measurements for all study patients. To assess the impact of pay for performance on blood pressure control over time, we calculated the proportion of patients with blood pressure less than 150/90 $\mathrm{mm} \mathrm{Hg}$ as a proportion of all patients with a measurement in each quarter. We also calculated the median, 25th, and 75th centile of the systolic and diastolic blood pressure for each quarter of observation and used longitudinal displays of the medians and centiles of systolic and diastolic blood pressures for the 23 consecutive quarters of the study. In addition to blood pressure values, we assessed the impact of the intervention on blood pressure monitoring itself by calculating the proportion of patients each month with a blood pressure measurement as a proportion of all study patients.

\section{Intensity of treatment}

We analysed the impact of pay for performance on intensity of treatment, which we conceptualised as the number of different antihypertensive drugs prescribed per patient. The NICE guidelines call for serially adding drugs to the therapeutic regimen of patients with persistent uncontrolled blood pressure. ${ }^{27}$ We determined for each month the proportion of patients receiving zero, one, two, and three or more classes of antihypertensive drugs as a proportion of all study patients. In addition, we created time series of newly
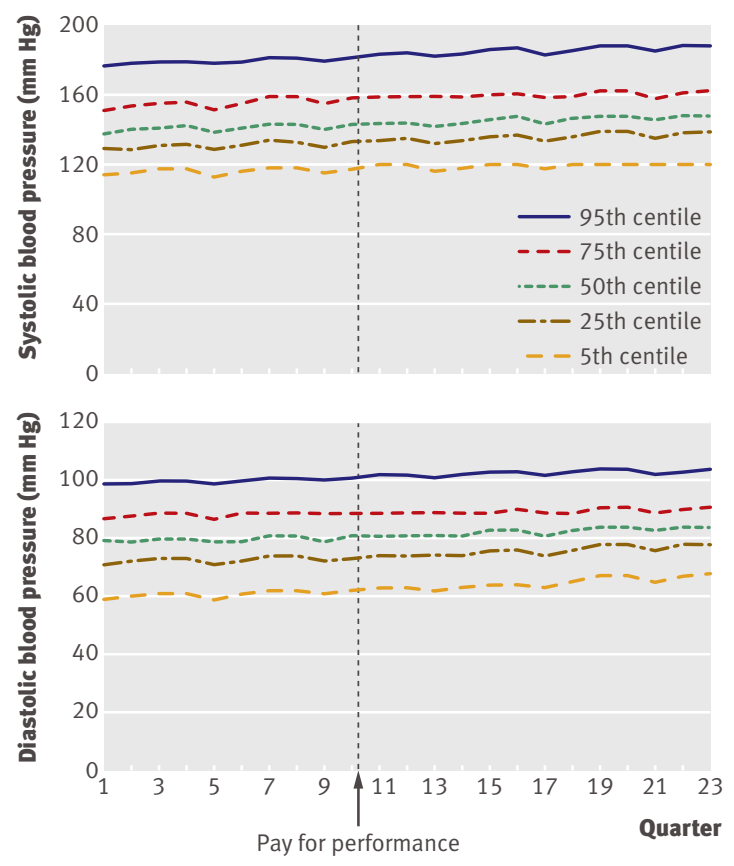

Fig 1| Time series of centiles of systolic and diastolic blood pressure in United Kingdom by quarter from January 2001 to July 2007 
treated patients each month as a proportion of all patients.

\section{Clinical outcomes}

We measured all cause mortality and incident cases of several hypertension related clinical outcomes (myocardial infarction, stroke, heart failure, and renal failure) based on previously validated Read codes. ${ }^{14161728}$ Specifically, we used Read codes in the categories G30, G34, and G35 for myocardial infarction; G61 and G64 to G68 for stroke; G23 and G58 for heart failure; and G22, 1Z1, K05, and K06 for renal failure.

To examine the effect of pay for performance on patients at different stages of hypertension, we carried out stratified analyses of the two subgroups of newly treated and treatment experienced patients to identify any changes in the cumulative incidence rate of hypertension related clinical outcomes and all cause mortality.

\section{RESULTS}

The table shows the characteristics of the study population $(\mathrm{n}=470725)$. Just over $60 \%$ was aged 55 years or older at the time hypertension was diagnosed. Distributions of age, sex, smoking status, socioeconomic status, diabetes, and depression were similar between the newly treated and treatment experienced subgroups.

\section{Blood pressure control}

Figure 1 shows the median and centiles (5th, 25th, 75 th, and 95th) of diastolic and systolic blood pressure for the study population for 23 consecutive quarters from January 2001 to July 2007. No clinically or statistically significant changes were observed in any levels or trends of these time series of blood pressure levels.

The proportion of patients with controlled blood pressure at the start of observation was about $70 \%$ (fig 2). This proportion showed a slight decreasing trend during the period before pay for performance at a rate of $-0.04 \%$ per month $(95 \%$ confidence interval -0.01 to $-0.08, \mathrm{P}=0.028)$, which continued after implementation of the initiative. After pay for performance had been implemented, the rate of controlled blood pressure did not change significantly for either level $(-1.19,95 \%$ confidence interval -2.06 to 1.09 , $\mathrm{P}=0.109)$ or trend $(-0.01,-0.06$ to $0.03, \mathrm{P}=0.569)$.

The time series of the percentage of patients with blood pressure measured each month increased slightly from about $45.6 \%$ at the start of observation (before pay for performance) at a rate of $0.15 \%$ per month $(95 \%$ confidence interval 0.03 to 0.34 , $\mathrm{P}=0.021$, fig 2). Changes in the frequency of blood pressure measurement after implementation of the pay for performance initiative did not differ significantly (level change $0.85,95 \%$ confidence interval -3.04 to $4.74, \mathrm{P}=0.669$ ) and trend change $-0.01,95 \%$ confidence interval -0.24 to $0.21, \mathrm{P}=0.615$ ).

\section{Treatment intensity}

During the 48 month baseline period a steady decline occurred in the proportion of patients receiving no drugs (baseline trend $-0.02 \%, 95 \%$ confidence interval -0.01 to $-0.04, \mathrm{P}=0.009)$ or only one $\operatorname{drug}(-0.22 \%$, -0.18 to $-0.24, \mathrm{P}<0.001$; fig 3$)$. A simultaneous increase was observed in the proportion of patients receiving combination therapy with either two drugs $(0.02 \%, 0.01$ to $0.03, \mathrm{P}<0.001)$ or three or more drugs $(0.19 \%, 0.18$ to $0.21, \mathrm{P}<0.001)$. Pay for performance was not, however, associated with any changes in these trends in drug prescribing. After the implementation of pay for performance, no change from baseline occurred in the proportion of patients receiving one drug (level change 0.07\%, 95\% confidence interval -0.83 to $0.98, \mathrm{P}=0.874$ and trend change $0.03 \%, 95 \%$ confidence interval -0.01 to $0.07, \mathrm{P}=0.190)$, two drugs $(0.03 \%,-0.19$ to $0.26, \mathrm{P}=0.805$ and $-0.01 \%,-0.01$ to $0.02, \mathrm{P}=0.431)$, or three or more drugs $(0.11 \%,-0.26$ to $0.47, \mathrm{P}=0.559$ and $0.02 \%,-0.15$ to $0.18, \mathrm{P}=0.142$ ).

During the baseline 48 month period before the implementation of pay for performance, $0.05 \%$ more patients per month started drug treatment (95\% confidence interval 0.03 to $0.06, \mathrm{P}<0.001$; fig 3$)$. After implementation, the rate of new drug treatment was continuous (level change $0.67,-1.27$ to $2.81, \mathrm{P}=0.412$ and trend change $0.02,-0.23$ to $0.19, \mathrm{P}=0.706)$.

\section{Major adverse medical outcomes}

Figure 4 shows the cumulative incidence rates (with 95\% confidence intervals) of patients experiencing any adverse clinical outcome (myocardial infarction, stroke, heart failure, or renal failure) or all cause mortality for the subgroup of patients whose treatment started before January 2001 (treatment experienced patients) and whose treatment was started six months before the implementation of pay for performance

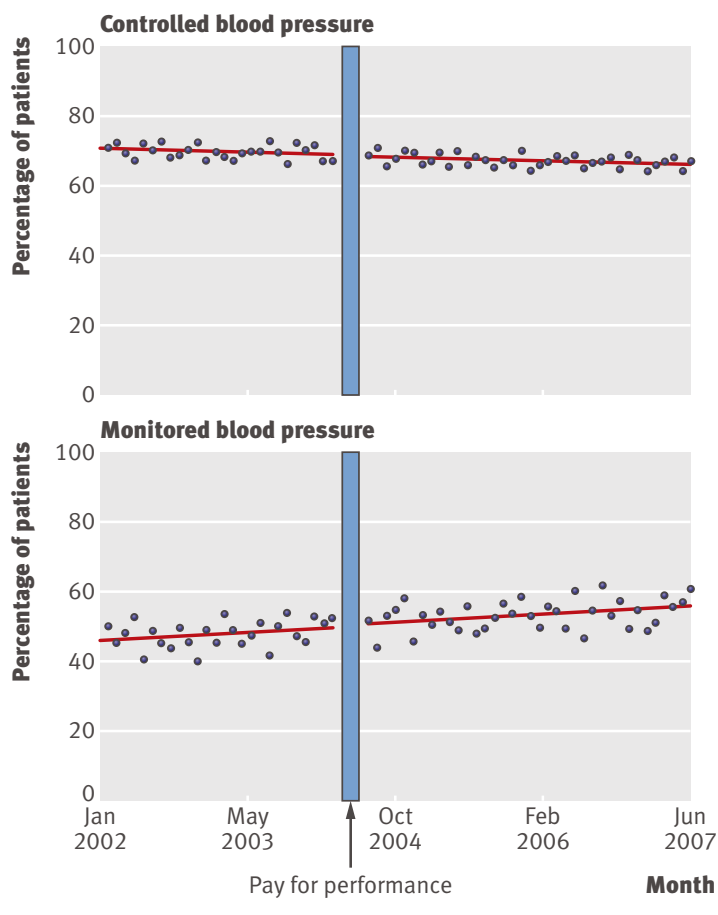

$\overline{\text { Fig } 2 \text { | Effect of pay for performance on blood pressure control }}$ and monitoring in United Kingdom 


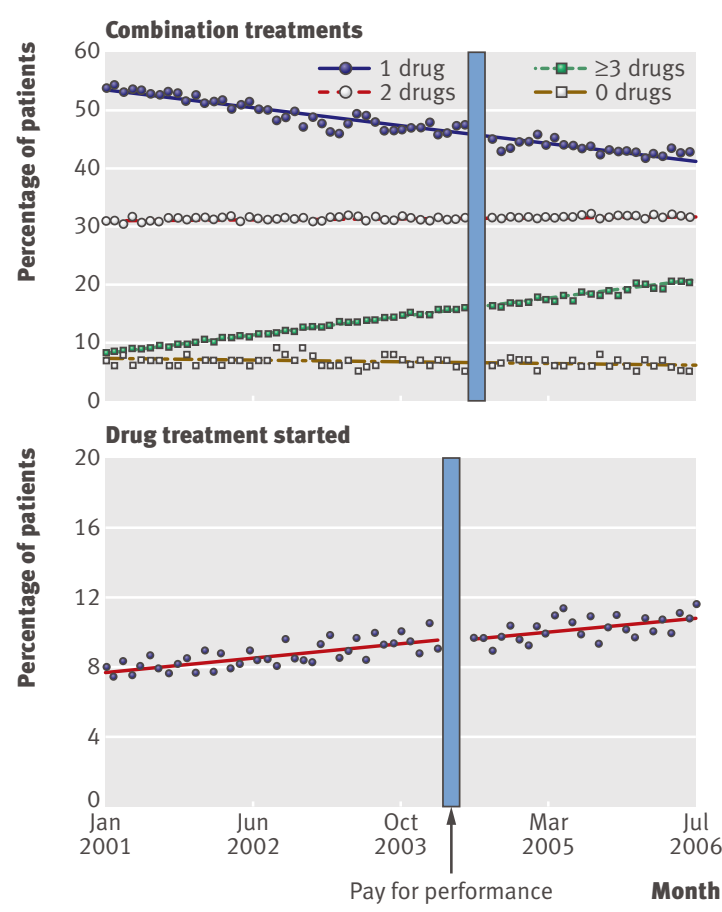

Fig 3 | Effect of pay for performance on intensity of treatment for hypertension in United Kingdom

(newly treated patients). Both subgroups were followed for 40 months after the implementation of pay for performance. The cumulative incidence of these clinical outcomes increased linearly, with tight confidence intervals for both subgroups.

When age, sex, smoking status, diabetes, and body mass index had been controlled for, no clinically or statistically significant discontinuities were observed in the cumulative incidence of experiencing a hypertension related clinical outcome in both subgroups after the start of pay for performance, or during the 36 months until the end of follow-up. Analysis of each of the hypertension related outcomes individually yielded similar results (data not shown).

Figure 4 also shows a time series of the composite end point of all cause mortality and adverse hypertension related outcomes during the entire study period. These outcomes showed a steady increasing trend before the intervention (baseline trend 0.04, 95\% confidence interval 0.02 to $0.06, \mathrm{P}<0.001)$. The level and trend for these adverse outcomes did not change significantly after the start of pay for performance (level change $0.07 \%, 95 \%$ confidence interval -0.13 to 0.28 , $\mathrm{P}=0.224$ and trend change $0.05 \%, 95 \%$ confidence interval -0.02 to $0.07, \mathrm{P}=0.257$ ).

\section{DISCUSSION}

Explicit financial incentives in the pay for performance initiative introduced in the United Kingdom in April 2004 did not improve the quality of care and clinical outcomes for patients with hypertension in primary care. Using a quasi experimental study design, we evaluated the impact of the policy on the quality of care and outcomes for hypertension in almost half a million patients and their general practitioners in the United Kingdom over seven years. Throughout the study period we observed steady improvements in the measurement of blood pressure and intensity of treatment. A simple before and after analysis would have produced spurious effects of pay for performance owing to lack of control for secular trends. Our study showed that the implementation of pay for performance had neither an immediately discernible (a level change) nor a sustained (a trend change) effect on the rate of blood pressure monitoring and control, despite these being among the compensated pay for performance measures. Furthermore, we did not find any statistically significant changes in the cumulative incidence of major hypertension related adverse outcomes or mortality after the implementation of pay for performance for the subgroups of treatment experienced and newly treated patients.

We found no evidence of gaming of the system to achieve quality targets. The level and trend for newly treated patients did not change after the implementation of pay for performance. We hypothesised that this measure would change because of the ease of implementation for general practitioners. (Doctors could have stepped up the treatment of patients with blood pressure close to control, resulting in an increase in the proportion of newly treated patients.) This lack of evidence for gaming is consistent with other studies. ${ }^{29}$

\section{Policy implications}

These findings may have several explanations. Firstly, given the observed improvements in quality of care indicators for hypertension in the years before pay for performance, such as more frequent monitoring of blood pressure and increasingly more aggressive treatment, doctors may have already been implementing the appropriate changes in practice to achieve the pay for performance standards. Although the financial incentives in the policy were considerable, it is possible that the pay for performance targets for hypertension were set too low and therefore doctors did not need to change behaviour significantly to attain them. A smaller study of the United Kingdom's pay for performance initiative, which evaluated the impact of this intervention on calculated clinical quality scores for selected conditions (but not controlling for secular trends), found that the policy led to short term, modest improvements in the quality of care for two conditions: asthma and diabetes. ${ }^{30}$ Once the targets were reached, however, improvements in quality slowed. This theory is supported by data from a survey of the level of attainment of intervention indicators in England, which showed that several quality indicators were rapidly achieved by most practices in 2004-5, the year the intervention was implemented. ${ }^{11} \mathrm{~A}$ similar high level of attainment was reported in 2007-8. ${ }^{31}$ Our study suggests that care for hypertension in the United Kingdom was already close (or along the way) to reaching the threshold required to achieve maximum payments set in the pay for performance policy. The setting of the indicator thresholds for maximum payment close 

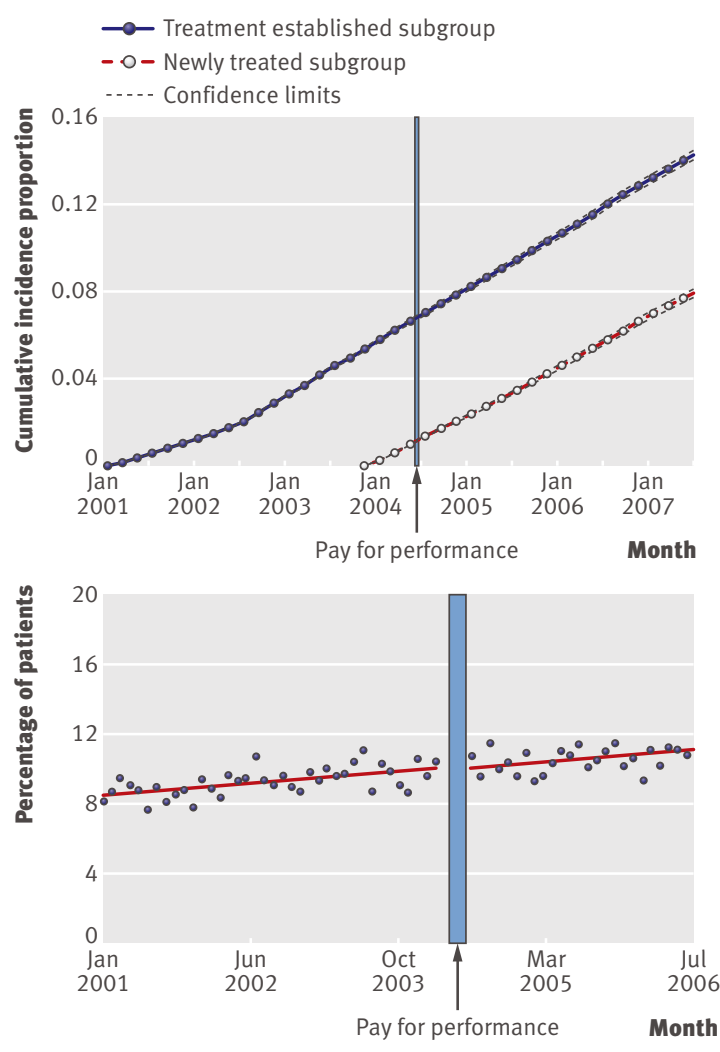

Fig 4 | Effect of pay for performance on hypertension related adverse outcomes (myocardial infarction, stroke, renal failure, heart failure) or on all cause mortality in United Kingdom

to prevailing practice may have provided little incentive for further improvement. Thus, pay for performance may have simply supported existing practice for hypertension.

In addition, pay for performance targeted a broad range of 136 clinical performance indicators and doctors may not have assigned the highest priority to the five hypertension related measures. It is possible that more attention may have been paid to more challenging indicators. That said, almost $20 \%$ of the available funds were directed at hypertension related performance, so it is unlikely that more effort and attention was paid to other performance measures. ${ }^{32}$ Implementing the broad range of pay for performance targets in a series of steps may achieve greater attention to, and improvement of, specific sets of quality measures.

Our study showed a lack of effect of pay for performance on clinical outcomes (cumulative incidence rates of myocardial infarction, stroke, heart failure, and renal failure). A systematic review of several smaller studies found similar results for doctors' financial incentives on patient level outcomes. ${ }^{1}$ The lack of impact of the pay for performance initiative on these long term adverse clinical outcomes is not surprising given its failure to affect the more intermediate outcome of blood pressure control, but at the least our study suggests no overt harms associated with implementation of pay for performance for hypertension related disease.
Strengths and limitations of the study

Our study has several limitations. Because the interventions were implemented in all four UK countries, we had no suitable comparison group. We were therefore unable to follow similar populations in which these interventions were not implemented. However, we were able to obtain data on prescribing, healthcare utilisation, and clinical outcomes for seven years, including three years before the intervention. The use of the strong quasi-experimental interrupted time series design enabled us to control for pre-existing levels and trends to detect any discontinuities in the outcomes studied at the point pay for performance was implemented. Adjusting for baseline trend in this way helps to control for most threats to internal validity. ${ }^{24}$ Moreover, the large sample size, tight indicator trend lines, and multiple types of outcome measures used in this study provide compelling evidence for the lack of effect of the pay for performance on hypertension care and outcomes.

Given the unique nature of the UK National Health Service, the generalisability of our results to other settings is potentially limited. The NHS is a homogenous single payer health system that provides coverage for all UK residents. This is unlike the health systems in many other industrialised countries. It is possible that pay for performance interventions may have different impacts in other types of healthcare systems. However, evidence from other studies of doctor interventions to improve quality suggests that doctors' behaviour is not necessarily different across health settings in industrialised countries. For example, two similar controlled trials in the United Kingdom and the United States failed to detect any impact of using computerised decision support to implement evidence based clinical guidelines for the management of asthma and angina in adults in primary care. ${ }^{3334}$

\section{Conclusion}

In summary, our study has shown that explicit financial incentives did not improve the quality of care and clinical outcomes for patients with hypertension in primary care in the United Kingdom. We found that the quality of care for hypertension was improving and already close to the threshold set for maximum payment in the pay for performance initiative. Some performance thresholds may have been set too low for the financial incentives to be effective.

In a setting such as the United Kingdom where several measures of quality of care were already on the path of continuous improvement, it seems that doctors may be less responsive to performance based monetary incentives to improve the care of hypertension than most policy makers believe. Effective alternative approaches to improving quality of primary care for hypertension exist, such as case management or $\mathrm{co}^{-}$ management of hypertension and other chronic conditions with allied health professionals such as nurses and pharmacists. ${ }^{35}$ Furthermore, evidence from studies of educational interventions suggests that fewer, simpler messages are more likely to achieve behaviour change 


\section{WHAT IS ALREADY KNOWN ON THIS TOPIC}

Systematic reviews have shown that the quality of care and intermediate outcomes of patients with hypertension can be improved by educational outreach programmes, comanagement in mixed professional teams, and engaging patients in their own care

Evidence from sufficiently large well controlled studies to support or disprove pay for performance as an effective tool to drive improvements in healthcare is scant, even for common conditions such as hypertension

Some studies have reported small and short lived positive effects, whereas others have suggested unintended harm

\section{WHAT THIS STUDY ADDS}

The large pay for performance initiative for primary care in the United Kingdom had no effect on processes of care and outcomes for patients with hypertension

The quality of care and outcomes for these patients were already improving before pay for performance was introduced; the initiative's lack of effect may be explained in part by performance targets that were set too close to existing practice

To stimulate further improvement in hypertension care in the United Kingdom, it may be necessary to implement other evidence based interventions on a large scale

than more complex, diffuse messages. ${ }^{36}$ Perhaps the resources devoted to pay for performance for hypertension would be better spent on implementing these interventions more widely.

Contributors: BS, SBS, DRD, FZ, AJA, and RAE conceived the study. All authors developed the methods and analysis for the study and contributed to the writing of the manuscript. BS and FZ carried out the analysis. All authors were involved in discussion and interpretation of the analysis. SBS is the guarantor.

Funding: This research received no specific grant from any funding agency in the public, commercial, or not for profit sectors.

Competing interests: All authors have completed the Unified Competing Interest form at www.icmje.org/coi_disclosure.pdf (available on request from the corresponding author) and declare: BS is supported by a fellowship in pharmaceutical policy research at Harvard Medical School. DRD, FZ, and SBS are investigators in the HMO Research Network Centre for Education and Research in Therapeutics and are supported by the Agency for Healthcare Research and Quality. SM receives salary support (health scholar) from the Alberta heritage foundation for medical research. All authors have no financial relationships with any organisations that might have an interest in the submitted work in the previous 3 years.

Ethical approval: This study was approved by the National Health Service North Nottinghamshire and Nottingham 1 research ethics committee. Data sharing: A detailed technical appendix and statistical code are available from the corresponding author at stephen_soumerai@hms.harvard.edu.

1 Petersen L, Woodard L, Urech T, Daw C, Sookanan S. Does pay for performance improve the quality of health care? Ann Intern Med 2006;145:265-72.

2 Shen Y. Selection incentives in a performance-based contracting system. Health Serv Res 2003;38:535-52.

3 Tanenbaum SJ. Pay for performance in Medicare: evidentiary irony and the politics of value. J Health Polit Policy Law 2009;34:717-46.

4 Maynard A, Bloor K. Will financial incentives and penalties improve hospital care? BMJ 2010;340:297-8.

5 Kearney P, Whelton M, Reynolds K, Muntner P, Whelton P, Jiang H. Global burden of hypertension: analysis of worldwide data. Lancet 2005;365:217-23.

6 Mancia G, De Backer G, Dominiczak A, Cifkova R, Fagard R, Germano G, et al. 2007 guidelines for the management of arterial hypertension: the task force for the management of arterial hypertension of the European Society of Hypertension (ESH) and of the European Society of Cardiology. J Hypertens 2007;25:1105-87.

7 Cushman W, Ford C, Cutler I. Success and predictors of blood pressure control in diverse North American settings: the Antihypertensive and Lipid-Lowering Treatment to Prevent Heart Attack Trial (ALLHAT). I Clin Hypertens 2002;4:393-404.

8 Chobanian A, Bakris G, Black H, Cushman W, Green L, Izzo J, et al. The seventh report of the Joint National Committee on prevention, detection, evaluation and treatment of high blood pressure. Arch Intern Med 2003;163:2413-46.

9 Roland M. Linking physicians' pay to quality of care-a major experiment in the United Kingdom. N Engl J Med 2004;351:1448-54.

10 Department of Health. The quality and outcomes framework. 2004 www.dh.gov.uk/prod consum dh/groups/dh_digitalassets/@dh/ @en/documents/digitalasset/dh_4088693.pdf.

11 National Health Service Information Centre. National quality and outcomes framework statistics for England 2005/2006. NHS Information Centre, 2006.

12 Shekelle P. New contract for general practitioners. $B M J$ 2003;326:457-8.

13 National Institute for Health and Clinical Excellence. Hypertension: management of adults in primary care, clinical guideline 18. NICE, 2004.

14 Epic-Cegedim. THIN data from EPIC: a guide for researchers. EPIC, 2007.

15 Bourke A, Dattani H, Robinson M. Feasibility study and methodology to create a quality-evaluated database of primary care data. Inform Prim Care 2004;12:171-7.

16 Lo Re V 3rd, Haynes K, Forde K, Localio R, Schinnar R, Lewis J. Validity of the health improvement network (THIN) for epidemiologic studies of hepatitis C virus infection. Pharmacoepidemiol Drug Saf 2009;18:807-14.

17 Lewis J, Schinnar R, Bilker W, Wang X, Strom B. Validation studies of the health improvement network (THIN) database for pharmacoepidemiology research. Pharmacoepidemiol Drug Saf 2007;16:393-401.

18 Soumerai S, Ross-Degnan D, Gortmaker S, Avorn J. Withdrawing payment for nonscientific drug therapy: intended and unexpected effects of a large scale natural experiment. /AMA 1990;263:831-9.

19 Wagner A, Ross-Degnan D, Gurwitz J, Zhang F, Gilden D, Soumerai S. Effect of New York state regulatory action on benzodiazepine prescribing and hip fracture rates. Ann Intern Med 2007;146:96-103.

20 Soumerai S, Ross-Degnan D, Avorn J, McLaughlin J, Choodnovsky I. Effects of Medicaid drug payment limits on admission to hospitals and nursing homes. N Engl / Med 1991;325:1072-7.

21 Stationery Office. Clinical terms (the Read codes) version 3 [program]. Stationery Office, 2007.

22 Wagner A, Soumerai S, Zhang F, Ross-Degnan D. Segmented regression analysis of interrupted time series studies in medication use research. J Clin Pharm Ther 2002;27:299-309.

23 Gillings D, Makuc D, Siegel E. Analysis of interrupted time series mortality trends: an example to evaluate regionalized perinatal care. Am J Public Health 1981;71:38-46.

24 Shadish W, Cook T, Campbell D. Experimental and quasiexperimental designs for generalized causal inference. Houghton Mifflin, 2002.

25 Kleinbaum D. Survival analysis: a self-learning text. Springer-Verlag, 1996.

26 Allison P. Survival analysis using the SAS system: a practical guide. 5th ed. SAS Institute, 2001.

27 National Institute for Health and Clinical Excellence. Hypertension: management of adults in primary care. NICE, 2006.

28 Bourke A, Dattani H, Robinson M. Feasibility study and methodology to create a quality-evaluated database of primary care data. Inform Prim Care 2004;12:171-7.

29 Persell S, Dolan N, Friesema E, Thompson J, Kaiser D, Baker D. Frequency of inappropriate medical exceptions to quality measures. Ann Intern Med 2010;152:225-31.

30 Campbell S, Reeves D, Kontopantelis E, Sibbald B, Roland M. Effects of pay-for-performance on the quality of primary care in England. $N$ Engl J Med 2009;361:368-78

31 National Health Service Information Centre. National quality and outcomes framework statistics for England 2007/2008. NHS Information Centre, 2008.

32 Doran T, Fullwood C, Gravelle H, Reeves D, Kontopantelis E, Hiroeh U, et al. Pay-for-performance programs in family practices in the United Kingdom. N Engl J Med 2006;355:375-84.

33 Eccles M, McColl E, Steen N, Rousseau N, Grimshaw J, Parkin D, et al. Effect of computerised evidence based guidelines on management of asthma and angina in adults in primary care: cluster randomised controlled trial. BMJ 2002;325:941-8.

34 Tierney W, Overhage J, Murray M, Harris L, Zhou X, Eckert G, et al. Effects of computerised guidelines for managing heart disease in primary care. J Gen Intern Med 2003;18:967-76.

35 Walsh J, McDonald K, Shojania K, Sundaram V, Nayak S, Lewis R, et al. Quality improvement strategies for hypertension management; a systematic review. Med Care 2006;44:646-57.

36 Soumerai S, Avorn J. Principles of educational outreach ("academic detailing") to improve clinical decisionmaking. JAMA 1990;263:549-56.

Accepted: 17 November 2010 